\title{
GÊNEROS DO DISCURSO, NARRATIVAS E AVALIAÇÃO NAS MUDANÇAS SOCIAIS: A ANÁLISE DE DISCURSO POSITIVA
}

\author{
(Genres, narratives and evaluation in social changes: \\ the Positive Discourse Analysis)
}

Orlando Vian Jr. ${ }^{1}$

(Universidade Federal do Rio Grande do Norte - UFRN)

\begin{abstract}
Martin's proposal (2004) of a Positive Discourse Analysis (PDA) is discussed in this article as a possible way of analyzing discourse from a systemic functional linguistics perspective. The narrative Amanhecer Esmeralda (Emerald Sunrise, my free translation) is analyzed from the genre and the appraisal perspective as a way of showing how narratives are a powerful tool in construing meaning and a possibility of using language to empower communities.
\end{abstract}

Key-words: Positive Discourse Analysis (PDA), Systemic Functional Linguistics (SFL), Genres, Appraisal, Narratives.

\section{RESUMO}

Discute-se neste artigo a proposta de Martin (2004) de uma Análise de Discurso Positiva (ADP), uma modalidade de análise de discurso a partir da perspectiva sistêmico-funcional de linguagem. A narrativa Amanhecer Esmeralda (Ferréz, 2005a) é utilizada como modo de mostrar as possibilidades de análise propostas por Martin e como os gêneros do discurso, o sistema discursivo da avaliatividade e as narrativas são elementos poderosos de construção de sentidos e um modo de utilizar a linguagem e o discurso para empoderar comunidades.

Palavras-chave: Análise de Discurso Positiva (ADP), Linguistica SistêmicoFuncional (LSF), Gêneros do discurso, Avaliatividade, Narrativas.

1. Mestre e doutor em Linguística Aplicada e Estudos da Linguagem. Atualmente é professor no Programa de Pós-Graduação em Estudos da Linguagem e no curso de graduação em Letras/Inglês da Universidade Federal do Rio Grande do Norte. 


\section{A Análise de Discurso Positiva}

A partir da perspectiva sistêmico-funcional de linguagem, Halliday (1985) argumenta que o texto constrói-se como uma unidade semântica e não como uma unidade gramatical, embora os significados sejam realizados por meio de fraseados. Logo, sem uma teoria dos fraseados não se pode apresentar a interpretação do texto. O autor (Halliday, 1985: xvii) ainda acrescenta que uma análise do discurso que não se baseia na gramática não é uma análise, mas apenas comentários sobre o texto, pois são as estruturas léxico-gramaticais que se realizam no texto e permitem que o significado seja construído, transmitido e, conseqüentemente, interpretado.

$\mathrm{O}$ interesse da Linguística Sistêmico-Funcional (LSF doravante) de Halliday pela análise do discurso, como nos informa Martin (2009), vem desde os trabalhos seminais de Halliday (1967) sobre tema e rema e dado e novo e, mais tarde, com o trabalho sobre os significados textuais que estão além da oração em seus estudos sobre coesão (Halliday; Hasan, 1976). Esse foco no discurso fica ainda mais explicito ao se observar a evolução dos estudos discursivos no escopo da LSF e se consolida na coletânea posterior dos trabalhos de Halliday (2002) dedicados ao texto e ao discurso.

O discurso, dessa forma, considerado pela perspectiva sistêmico-funcional deve ser compreendido como a manifestação dos processos lingüísticos e como estes circulam e são utilizados, identificados e reconhecidos pelos usuários em contextos sociais específicos de uso (Hasan, 2004: 14).

A partir desse prisma, Martin propõe o que chama de Análise de Discurso Positiva (ADP, doravante), apresentando-a, em um primeiro momento, como um estilo de análise que se imiscui com processos sociais de mudança que percebemos como possíveis de transformar o mundo em um lugar melhor (Martin, 2004).

Posteriormente, Martin e Rose (2004: 264) sugerem que a proposta de uma ADP está embasada no fato de que é necessário um foco complementar na comunidade, que leve em consideração o modo como as pessoas se agregam e buscam locais para si mesmas no 
mundo, de modo a redistribuírem o poder sem, necessariamente, lutar contra ele.

Aqui, portanto, há uma alusão à Análise de Discurso Crítica (ADC, doravante), conforme proposta por Fairclough (2003) e que, segundo Martin, pode ser complementada pela ADP, no sentido de que a ADP coloca seu foco em discursos que são elaborados para tornar o mundo um lugar melhor, ao passo que a preocupação mais tradicional da ADC, com discursos a serviço do poder abusivo (Martin, 2006: 178) e intervenção é o que motiva o interesse pela pesquisa na relação entre linguagem e ideologia. Essa alusão direta à $\mathrm{ADC}$, deve ser compreendida como complementaridade e não como justaposição ou paralelismo disciplinar, como sugere KhosraviNik (2007), por exemplo.

Para que o poder seja redistribuído, no entanto, é necessário que o compreendamos, porque não podemos redistribuir o que não entendemos (Martin e Rose, 2003). E aqui temos o ponto de contato entre a ADC e a LSF de Halliday, conforme sinalizados pelos autores: onde a ADC tem se ocupado com a análise do discurso que sustenta as desigualdades, a LSF ultrapassa esta fronteira e está igualmente preocupada com o redirecionamento das desigualdades. Nesse ponto, sem dúvida, surge o questionamento: como isso pode ou deve ocorrer? Como tais desigualdades podem ser redirecionadas?

A resposta está no fato de que as conclusões e respostas a que o analista chega com base em suas pesquisas deve servir à comunidade e a seus cidadãos de forma a conscientizá-los de seu papel perante o mundo para que o compreendam e possam proceder a tal redistribuição. No caso das experiências vivenciadas pelos autores, incluem-se os projetos desenvolvidos na Austrália com minorias aborígines, por exemplo, ou com o ensino a comunidades minoritárias. Trabalhos desenvolvidos no Brasil apontam para o uso de gêneros e a linguagem como elemento para empoderar comunidades de prática em contato com forças hegemônicas, como o aprendizado instrumental de idiomas para atender necessidades específicas, como relatado em Vian Jr. (2002).

Neste artigo, o texto de Amanhecer Esmeralda (Ferréz, 2005a) é colocado sob a lente da ADP para que se observem as possibilidades de 
análise propostas por Martin e como os gêneros do discurso, o sistema discursivo da avaliatividade e as narrativas são elementos poderosos de construção de sentidos e um modo de utilizar a linguagem e o discurso para empoderar comunidades.

\section{Categorias de análise}

A proposta de uma ADP, conforme sugerida por Martin, parte de estudos anteriores (p. ex., Martin, 1992, Halliday e Hasan, 1976), e está sedimentada no papel da gramática como transcendente à estrutura gramatical e no pressuposto de que há uma relação entre a organização da linguagem e a organização do contexto social, como estabelece Halliday (1978), ou seja, os significados construídos pelas metafunções ideacional, interpessoal e textual são a realização das variáveis contextuais de registro: campo, relações e modo, na seguinte interrelação:

Quadro 1: Relação variáveis de registro/metafunções

\begin{tabular}{|c|c|}
\hline Variável de registro & Metafunção \\
\hline Campo & Ideacional \\
\hline Relações & Interpessoal \\
\hline Modo & Textual \\
\hline
\end{tabular}

Partindo-se dos recursos coesivos de referência, elipse, substituição, conjunção e coesão lexical inventariados por Halliday e Hasan (1976), a proposta inicial de Martin (1992) compreendia a reformulação de tais recursos como estruturas semânticas discursivas configuradas como identificação, negociação, conjunção e ideação. Em trabalho posterior (Martin e Rose 2003, 2007), esses sistemas discursivos são ampliados e, além dos quatro anteriomente mencionados, agregam-se os sistemas de avaliatividade e de periodicidade. Cada um desses sistemas exerce uma função que contribui para a construção do sentido na organização textualdiscursiva, na seguinte correspondência: 
Quadro 2: Os sistemas discursivos e suas funções

\begin{tabular}{|l|l|}
\hline \multicolumn{1}{|c|}{ Sistema discursivo } & \multicolumn{1}{c|}{ Função } \\
\hline Ideação & Representar a experiência \\
\hline Conjunção & Relacionar eventos \\
\hline Avaliatividade & Negociar atitudes \\
\hline Negociação & Deflagrar trocas \\
\hline Identificação & Rastrear pessoas e coisas \\
\hline Periodicidade & Seguir o fluxo de informações \\
\hline
\end{tabular}

A noção de estratificação também deve ser considerada aqui: do mesmo modo que as metafunções no estrato léxico-gramatical, os sistemas discursivos compõem o estrato semântico-discursivo, possibilitando a análise das relações coesivas como a estrutura discursiva. Pode-se, assim, estabelecer a relação entre os sistemas discursivos e as metafunções, como ilustrado no Quadro 3:

\section{Quadro 3 - Relações entre a metafunções e os sistemas} discursivos

\begin{tabular}{|l|l|}
\hline Metafunção & \multicolumn{1}{|c|}{ Sistema discursivo } \\
\hline \multirow{2}{*}{ Ideacional } & Ideação \\
\cline { 2 - 2 } & Conjunção \\
\hline \multirow{2}{*}{ Interpessoal } & Avaliatividade \\
\cline { 2 - 2 } & Negociação \\
\hline \multirow{2}{*}{ Textual } & Identificação \\
\cline { 2 - 2 } & Periodicidade \\
\hline
\end{tabular}

(adaptado de Martin e Rose, 2005)

Ao sugerir uma ADP, a proposta de Martin está sedimentada em três parâmetros: (a) no gênero e em sua renovação na sociedade; (b) nos sistemas discursivos e, aqui, por uma questão de espaço, restringirnos-emos à linguagem avaliativa, ou seja, ao sistema de avaliatividade e, por fim, (c) na função da narrativa nas relações humanas e nos diversos contextos de prática. 


\section{a) Gêneros do discurso}

Em termos sistêmico-funcionais, os gêneros podem ser definidos como processos sociais organizados em estágios e orientados por um propósito (Martin e Rose, 2008: 6). Os autores consideram ainda os gêneros como uma configuração recorrente de significados que mobilizam práticas sociais em uma dada cultura.

Podemos afirmar, desse modo, que os gêneros são acionados toda vez que uma interação social ocorre. No entanto, é necessário que se concebam os gêneros não como elementos individuais, mas como estes relacionam-se e organizam-se em famílias de gêneros, já que estão em constante evolução, transformação, adaptação, pois novos eventos sociais acionam novos gêneros para seus contextos de uso e, desse modo, as mudanças sociais fazem emergir gêneros que funcionam, literalmente, como agentes de mudanças sociais.

Tais gêneros funcionam, ao mesmo tempo, como forma de legitimação, o que traz consigo o conhecimento de um novo universo outrora desconhecido ou ainda não desvelado a determinadas classes sociais.

Tomemos o caso da literatura marginal no Brasil. Trata-se de um movimento que se iniciou de forma sutil, absolutamente despercebido dos meios de comunicação (ou propositadamente ignorado, há que se considerar). Ao contrário da literatura de auto-ajuda, por exemplo, amplamente divulgada pela mídia e automaticamente incorporada às praticas sociais contemporâneas, afinal, é preciso que todos se beneficiem das mais despropositadas teorias trazidas pela auto-ajuda. Rapidamente, as listas de publicações de auto-ajuda cresceram a tal ponto de as grandes revistas de circulação nacional criarem uma nova seção, nos livros mais vendidos, apenas para os livros de auto-ajuda, além de ficção e não-ficção.

A literatura marginal, por outro lado, é absolutamente, num proposital jogo de palavras, marginalizada. Não há interesse da mídia em divulgar a literatura marginal, afinal, trata-se de uma realidade que não quer ser conhecida por muitos e que não deve ser mostrada, embora haja a produção de textos produzidos na periferia, como o caso 
da coletânea organizada por Férrez (2005b) com textos de autores da periferia de diversas metrópoles do Brasil.

No estudo da relação entre a literatura marginal e a tradição da literatura, Justino (2007: 191-2) sinaliza que o texto de Férrez no prefácio da Terrorismo Literário apresenta

"de maneira contundente a relação entre um lugar de pertença, a favela
e a 'perifa', e a posição de quem escreve quanto ao público consumidor
da literatura e a desigualdade na distribuição dos bens culturais e na
sua hierarquização. Neste sentido, na medida em que reconfigura a
própria noção de literatura e suas práticas, o texto de Ferréz, contém
um posicionamento sobre a tradição literária".

Há que se distinguir, também, a literatura marginal, produzida à margem da sociedade, como os textos de Férrez e Sacolinha, e a literatura sobre a marginalidade, produzida por autores como Rubem Fonseca ou Patrícia Melo.

As mudanças sociais e o advento das novas tecnologias da informação e da comunicação fizeram emergir novos modos de comunicação e, com eles, novos gêneros e novos suportes, que são verdadeiros agentes de mudanças sociais, uma vez que as comunidades sofrem alterações devido à assimilação dessas novas práticas. Basta um olhar de relance para os novos recursos multimodais e percebemos a forma como a dinâmica social foi alterada em função de novos redes sociais e os gêneros exigidos para a interação em tais redes como Orkut, Twitter ou Facebook, apenas para citar três exemplos.

A partir do momento que passam a fazer parte dos novos modos de interação, essas novas possibilidades passam a funcionar como formas de legitimação e, consequentemente, torna-se necessário o seu entendimento para que se compreenda a sua dinâmica e como impactam diretamente nas interações e, por conseguinte, no modo como a linguagem adapta-se para atender às necessidades do usuários. O internetês é um excelente exemplo disso, já que um usuário, para legitimar-se na comunidade, deve seguir algumas normas prescritas no que diz respeito ao uso da linguagem e sua apropriação ao contexto. 


\section{b) Avaliatividade}

A metafunção interpessoal, na gramática sistêmico-funcional de Halliday (1985, 1994, 2004), realiza léxico-gramaticalmente a interação, ou seja, é função da oração negociar proposições, que se realizam através de declarações, perguntas e respostas a tais proposições. Além disso, negociam-se propostas, realizadas por meio de ofertas, comandos e respostas a tais propostas.

Ao tratarmos de emoções, no entanto, é necessário que atravessemos uma fronteira além dos recursos disponíveis nesses sistemas e que olhemos a léxico-gramatica por uma perspectiva lexical.

Faz-se mister, portanto, recorrermos a um sistema que inclua formas utilizadas para que graduemos os significados de forma a construirmos nossas avaliações em relação às informações que trocamos.

O sistema de avaliatividade proposto por Martin e White (2005) lida com os mecanismos de avaliação disponíveis na linguagem a partir de três universos: afeto, julgamento e gradação, ou seja, a forma como realizamos léxico-gramaticalmente emoção, ética e estética.

Dentre os seis sistemas discursivos (veja Quadros 2 e 3), optamos pelo sistema de avaliatividade, pois é a partir de nossas atitudes perante nossos interlocutores em interações que as comunidades são formadas.

O modocomoconstruímos e realizamos linguisticamentenossas avaliações veicula a forma como expressamos nossos sentimentos em relação aos usuários nos contextos em que estamos inseridos, ou seja, os significados avaliativos expressados ao construirmos os sentimentos em nossos textos será um fator determinante na construção de valores e circulação do poder nas comunidades.

Como sistema de significados interpessoais, o sistema de avaliatividade trata dos recursos disponíveis na língua para que sejam negociadas as relações sociais. Os recursos desse sistema ainda explicitam as atitudes do autor/falante, isto é, a maneira como se sente ou se posiciona em relação às coisas e às pessoas que avalia, além de considerações sobre a fonte a que são dirigidas as avaliações, o que, exatamente está sob avaliação. 
As opções básicas de avaliatividade incluem três subsistemas: engajamento, atitude e gradação e cada um deles reconfigura-se em outros subsistemas, de acordo com os recursos disponíveis para as avaliações na linguagem, representado no seguinte sistema básico:

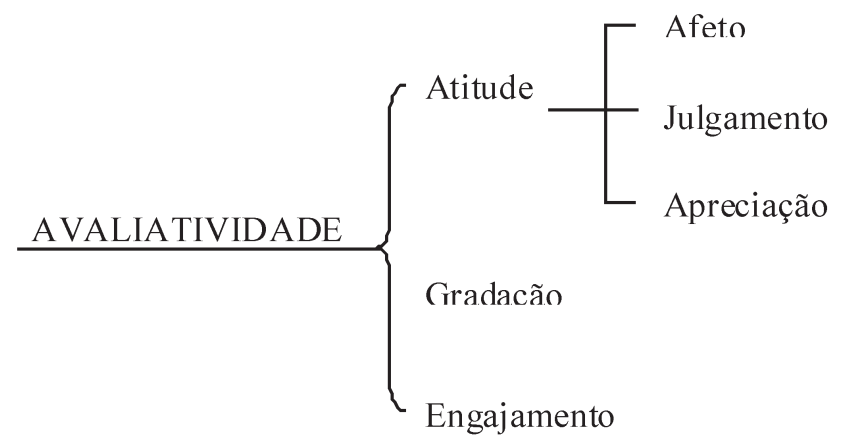

Figura 1 - Recursos do Sistema de Avaliatividade e do Subsistema de Atitude. Fonte: Martin; White (2005, p. 38).

No caso do texto de Amanhecer Esmeralda, os recursos lexicais utilizados para a construção dos sentidos avaliativos estão geralmente em contraste, pois o autor contrasta dois mundos: o sofrimento e os sentimentos negativos da favela e de seus habitantes e os sentimentos positivos e as transformações ocorridas.

Desse modo, os recursos de gradação são recorrentemente utilizados no início da narrativa, por exemplo, para sugerir ao leitor a questão do espaço exíguo no barraco, bem como a pequenez da menina, como ilustram os exemplos abaixo:
pequena mesa feita artesanalmente
pequena calça jeans
uma blusinha vermelha
pequeno cômodo
pequeno espelho
pequenas mãos 
Após ter feito sua trança pela merendeira da escola, Dona Ermelinda, ocorre com Manhã o processo de transformação e o resgate de suas raízes africanas, que vai extrapolar o individual e o ambiente do barraco, ampliando-se para o contexto em que vivem. Quando Manhã chega à casa depois da aula e com sua trança e o pai, bêbado, vê seu cabelo, percebe a beleza da filha, o texto é caracterizado pela constante recorrência aos recursos avaliativos de apreciação positiva e que levarão, posteriormente, à transformação, conforme as seguinte ocorrências:

\author{
aquela linda menina \\ estando linda como nunca. \\ Você tá linda. \\ essas tranças bonitas \\ uma menina tão bonita \\ você é muito linda
}

Os dois últimos exemplos mostram a associação de um recurso de apreciação acentuado pelo uso de recursos de gradação.

A partir dessa constatação, o pai conclui que a menina está muito linda para morar num lugar feio e resolve pintar o barraco e assim ocorre a transformação da comunidade e, no desfecho da narrativa, depois da transformação, tudo que era pequeno passou a ser grande, organizado e bonito:

\title{
uma casa bonita
}

um lindo espelho grande

tudo estava muito lindo, organizado

Por se tratar de um assunto bastante amplo, desenvolvido detalhadamente em Martin e White (2005) para a língua inglesa e abordado de modo introdutório para a língua portuguesa em Vian Jr (2009), remetemos os leitores as esses trabalhos para uma apreensão mais ampla dos mecanismos, sistemas e subsistemas de avaliatividade concebidos por Martin e White. 


\section{c) Narrativa}

É inquestionável o papel da narrativa na história da humanidade e, mais que isso, de seu poder político. Acresça-se o fato de que a avaliação exerce um papel primordial nas narrativas e assume grande significância, pois o modo como narramos nossas experiências são quase inerentemente avaliativos, pois os fatos, emoções, sentimentos, eventos e todas os aspectos narrados são, mesmo que indiretamente ou inconscientemente, avaliados pelo narrador, pois este narra determinado evento com base em seu posicionamento ideológico na sociedade em que vive. É necessário que consideremos, portanto, os valores de significância social que atribuímos ao recontarmos eventos.

Compreender o modo como a narrativa circula nos contextos de situação e seu papel social na construção das identidades e das comunidades, bem como compreender seus aspectos tipológicos e topológicos (Martin e Rose, 2008), ou seja, o modo como os gêneros narrativos organizam-se em relação aos demais e como são estruturados internamente, cria um universo de possibilidades para a compreensão da circulação dos gêneros nas comunidades.

O estudo da narrativa e sua organização, estruturação e circulação trazem à tona aspectos para que se possa pensar no mapeamento do contexto situacional e cultural e, por conseguinte, da cultura em que o texto é produzido e compreender como as relações sociais são construídas nos textos.

Diversos são os estudos em variadas áreas que estudam as narrativas. Propp (2006), em seu estudo sobre a morfologia de um corpus de 100 contos maravilhosos, estabelece como pressuposto o fato de que a narrativa apresenta em sua composição partes essenciais ou genéricas e partes contingentes ou específicas, do mesmo modo que qualquer outro organismo humano vegetal ou mineral.

Nessa mesma abordagem descritiva, mas por uma outra perspectiva, Labov $(1972,1982,1997)$ procede à descrição de narrativas orais de experiências pessoais, apontando para sua constituição em 
uma sequência de estágios funcionais, na função que cada um deles contribui para a composição do todo.

Nos campo dos estudos literários, a narrativa por ser concebida como "todo discurso que nos apresenta uma história imaginária como se fosse real, constituída por uma pluralidade de personagens, cujos episódios de vida se entrelaçam num tempo e num espaço determinado" (D’Onofrio, 2007: 46)

As narrativas, por essa razão, constituem um macro-gênero (Martin e Rose, 2008) e, em relação à sua estrutura e aos estágios que as organizam, consideramos a narrativa a partir de quatro estágios: (1) introdução - embora Martin e Rose utilizem em inglês o termo orientation, preferimos 'introdução', já que o que se controi é a introdução da narrativa, podendo ser usados ainda os termos exposição, apresentação ou mesmo orientação, como tradução literal do termo inglês orientation; (2) desenvolvimento (ou complicação), (3) clímax e (5) desfecho (ou desenlace ou conclusão - o termo em inglês usado por Martin e Rose (2008) é coda, mas como esse termo é utilizado em português no campo musical, como sendo a seção que encerra uma música, utilizaremos o termo desfecho para tratar da narrativa, sendo ainda comuns os usos dos termos resolução, desenlace ou conclusão.

\section{A análise de Amanhecer esmeralda}

A partir das possibilidades de análise sugeridas por Martin e com base nos três aspectos anteriormente apresentados: gênero, narrativa e avaliação, procedemos à análise de alguns aspectos da narrativa Amanhecer esmeralda (Ferréz, 2005a), em que o autor narra a história de Manhã.

A perspectiva aqui adotada concebe gênero conforme propõem Martin e Rose (2008: 231), isto é, como configurações de significados e, a partir dos estudos sobre tipologia e topologia dos gêneros, é possível mapear a cultura como um sistema de gêneros. Além do fato 
de que a linguagem tem uma relação dialética com o contexto social em que é produzida e, por essa razão, o texto traz em si marcas do contexto.

A narrativa de Amanhecer Esmeralda é ilustrada por Igor Machado e, em função disso, poderia também ser considerada a partir de uma perspectiva multimodal ou de sua gramática visual (Kress e van Leuween, 1996), mas como nosso intuito é discutir a perspectiva da ADP de Martin, a discussão restringe-se a alguns dos elementos verbais.

A partir dos quatro estágios expostos anteriormente como componentese estruturantes da narrativa (introdução, desenvolvimento, clímax, desfecho), o texto está organizado do seguinte modo:

\section{(i) Introdução}

Nessa parte da narrativa, o autor nos apresenta Manhã e o contexto em que esta vive: uma favela na periferia de São Paulo. São Paulo não é explicitamente mencionada na narrativa, mas pelas referências contextuais e do autor da obra, essa informação é facilmente inferível. O estágio é assim realizado:

Manhã acordou cedo mais uma vez, era sexta-feira, o dia de alegria para todas as crianças que estudavam. Foi até a pequena mesa feita artesanalmente por seu pai com tábuas de caixotes e não viu nenhum embrulho. Era mais um dia sem pão. Pegou a panela onde sua mãe fazia café e olhou dentro, nada.

\section{(ii) Desenvolvimento}

No desenvolvimento da história, o leitor toma contato com a vida na escola e com os questionamentos do professor de português, Marcão, sobre a menina, o fato de estar sempre mal-vestida e outros aspectos de sua vida. O professor pondera:

Marcão então começou a entender por que ela vinha tão malvestida para a escola, e continuando a conversa, descobriu que ela mesma, ao chegar em casa, fazia os deveres domésticos, cozinhava para comer, 
lavava a própria roupa, ou seja, com apenas nove anos de idade, Manhã já tinha a responsabilidade de uma mulher.

Nesse estágio da narrativa, também são apresentados ao leitor outros aspectos do dia-a-dia de um morador de uma favela e sobre a vida na periferia de uma grande cidade como São Paulo.

\section{(iii) Clímax}

Após sermos apresentados à rotina de Manhã, bem como elementos de seu cotidiano, o clímax ocorre quando o professor de português procede a duas ações que levam à transformação. Primeiramente, Marcão dá a Manhã um tecido de cor esmeralda e, em seguida, apresenta Manhã à Dona Ermelinda, a merendeira da escola, que sugere que Manhã deve fazer uma trança, como a das princesas africanas, ancestrais de Manhã. A merendeira afirma:

- Então, toda menina afro-descendente devia fazer isso, usar mais os cortes que têm a ver com o nosso povo, com a nossa história.

Esses dois elementos reencaminham a história e levam à transformação. A partir daí, os pais de Manhã ficarão impressionados com a beleza da filha, o que deflagrará mudanças na comunidade, no contexto mais amplo em que vivem e iniciarão mudanças em sua casa e em sua comunidade.

\section{(iv) Desfecho}

O desfecho da história de Manhã ocorre a partir da transformação. Após a descoberta de si, de sua condição social, de sua história, de sua etnia, Manhã volta ao ritmo normal e à sua rotina, mas agora em um mundo transformado.

Os pais da menina, motivados por sua transformação, mobilizam outras mudanças e o que no início da narrativa são problemas à menina passam a ser aspectos positivos: 
Foi ao banheiro e não teve que molhar o cabelo, pois as tranças estavam do jeito que foram feitas. Olhou bem para o rosto no espelho, e viu pela primeira vez os traços daquela rainha africana que Dona Ermelinda havia falado. Não tinha mais vergonha do nariz, não tinha mais vergonha de sua boca, era assim que a rainha devia ser.

Por fim, Manhã passa a ver as coisas de nova forma, metaforizado pela cor esmeralda, a cor do vestido que vestia e o estágio realiza-se da seguinte maneira:

Pegou seu material no sofá, saiu e fechou a porta. Quando chegou à rua, não acreditou, todas as casas estavam pintadas, tudo estava muito lindo, organizado como nunca tinha visto, ela olhou para seu vestido, olhou para o as casas, olhou para o céu, e viu que tudo era daquela cor, até o amanhecer era esmeralda.

A narrativa de Ferréz, com base na análise dos estágios que a compõem é eficiente em sua avaliação e mostra como a linguagem pode empoderar comunidades para promover mudanças.

\section{Considerações finais}

A perspectiva de se conhecer para se posicionar é facilmente perceptível no texto de Ferréz. Em vez de criticar a pobreza, a favela, o modo de vida ou qualquer outro aspecto da vida, como já o fizera em obras como Manual Prático do Ódio (Ferréz, 2003) e Capão Pecado (Ferréz, 2005c), o autor opta, nessa obra, por empoderar os membros da comunidade a perceberem seu potencial e, desse modo, poderem proceder às mudanças em seu contexto. Manhã descobre suas origens. A revolta com seu cabelo, revelada no início da história, transforma-se em admiração a partir da história contada por Dona Ermelinda das princesas africanas. 
Eis aí a proposta contida na análise positiva proposta por Martin: ao conhecermos a comunidade, é possível rever a circulação dos textos e dos gêneros que nela são veiculadas, pois são eles que podem empoderar os usuários que nela interagem, possibilitando a compreensão do individual, do pessoal, do local e sua integração como parte do global, ampliando as perspectivas de vida nas comunidades. Essa perspectiva pode ainda auxiliar na compreensão para que se aprenda a conviver na 'nova' realidade, realidade essa que traz consigo novos gêneros que, uma vez empreendidos, permitem a ampliação de horizontes.

A abordagem de análise de discurso positiva proposta permite uma maior aproximação para a percepção da linguagem como um meio de inserção social e um modo mais realista de olhar a questão das variações e da relação entre linguagem/contexto, reforçando o aspecto da relação entre texto-gramática-discurso.

Afinal, tentar fazer do mundo um lugar melhor pode ser de grande valia, pois é que parece fazer parte da busca pela felicidade em um mundo tão controverso. Ao discutir a noção de felicidade e seu percurso desde os pré-socráticos até a contemporaneidade, Silva (2007) aponta, de forma bastante negativa, com um vaticínio esse cenário:
"Nesse sentido é que se pode dizer que a riqueza de meios é proporcional à pobreza dos fins, e que a pletora de realizações científicas convive com a indigência ética: um grande poder e um grande vazio comum, numa convergência perigosa, não apenas para desorientar o indivíduo, mas também para induzi-lo a reduzir drasticamente o horizonte de sua humanidade. Diante de tantas e tamanhas desilusões, não somente apontadas pela crítica, mas, sobretudo, vividas dramaticamente na experiência histórica do século $\mathrm{XX}$, a era das guerras totais e dos genocídios, como se pode seguir depositando confiança no curso objetivo da história e esperança no predomínio de valores que levem à felicidade como fruto do progresso?"

Nesse universo em progresso e marcadamente pessimista e individualista como sugerem estudos no campo da Filosofia, como os de Lipovetsky (2007) com o seu modelo "consumista-emocionalindividualista” para as diferentes idades, ou da Sociologia, como 
propõe Baumann (2001: 77), para quem devemos cuidar de nossos problemas, e apenas de nossos problemas, com a consciência limpa, uma sociedade individualista em que a análise de discurso positiva apresenta-se como um modo de empoderamento pela linguagem e de importância crucial nas transformações sociais.

\section{Referências bibliográficas}

BAUMAN, Z. Modernidade Líquida, Rio de Janeiro: Jorge Zahar Editor, 2001.

D’ONOFRIO, S. Forma e sentido do texto literário. São Paulo: Editora Ática, 2007.

FERRÉZ. Manual prático do ódio. Rio de Janeiro: Editora Objetiva, 2003. . Amanhecer Esmeralda. Ilustrações: Igor Machado. Rio de Janeiro: Editora Objetiva, 2005a.

. Capão Pecado. Rio de Janeiro: Editora Objetiva, 2005b.

(org.). Literatura marginal: talentos da escrita periférica. Rio de Janeiro: Agir, 2005c.

FAIRCLOUGH, N. 2003. Analysing discourse: textual analysis for social research. London; New York: Routledge.

HALLIDAY, M.A.K. 1967. Notes on transitivity and theme in English. Journal of Linguistics 3(1), 37-81, 3(2), 199-244, 4(2), 179-215, 1967/8

. Language as social semiotic: the social interpretation of language and meaning. London: Edward Arnold, 1978.

. 1985 An Introduction to functional grammar. Londres: Edward Arnold. .1994. An introduction to functional grammar. Londres: Edward Arnold. $2^{\text {nd }}$ edition.

. Linguistic studies of text and discourse, volume 2 in the Collected works of M.A.K. Halliday. J. Webster (ed.). Continuum, 2002.

- 2004. An introduction to functional grammar. Revisada por MATHIESSEN, Christian M.I.M. London: Arnold. $3^{\text {rd }}$. Edition.

HALLIDAY, M.A.K.; HASAN, R. Cohesion in English. London: Longman, 1976. 
. Language, context, and text: aspects of language in a social-semiotic perspective. Oxford: Oxford University Press, 1989.

JUSTINO, L.B. A literatura marginal e a tradição da literatura: o prefáciomanifesto de Ferréz, "Terrorismo Literário". Gragoatá 192 Niterói, n. 23, p. 189-203, 2. Sem, 2007.

KHOSRAVINI, M. Positive Discourse Analysis? Lancaster Maze.

http://lancastermaze.blogspot.com/2007/02/positive-discourse-analysis. html. Acesso em 02.set.10

KRESS, G.; VAN LEEUWEN, T. Reading images: the grammar of visual design. Routledge: London, 1996.

LABOV, W. The transformation of experience in narrative syntax. Language in the Inner City. Philadelphia: Pennsylvania University Press, 1972.

. Speech actions and reactions in personal narrative. In D. Tannen (ed.), Analyzing Discourse: Text and talk. Washington D.C.: Georgetown University Press, 1982. pp. 219-247, 1982.

. Some further steps in narrative analysis. Journal of Narrative and Life History 7.1-4. 1997: 395-415.

LIPOVETSKY, G. A felicidade paradoxal: ensaio sobre a sociedade de hiperconsumo. São Paulo,Companhia das Letras, 2007.

MARTIN, J. R. English text - systems and structure. Philadelphia/Amsterdam: John Benjamins Publishing Company, 1992.

. Blessed are the peacemakers: reconciliation and evaluation. In: C. Candlin (ed.) Research and practice in professional discourse. Hong Kong: City University of Hong Kong Press, 187-227. 2002

. Positive discourse analysis: power, solidarity and change. Revista Canaria de Estudios Ingleses, n. 49, 2004.

. Vernacular deconstruction: undermining spin .D.E.L.T.A., vol. 26, no. 2, pp. 177-203. 2006.

. Discourse studies. In: HALLIDAY, M.A.K.; WEBSTER, J.J. Continuum companion to systemic functional linguistics. London: Continuum, 2009.

MARTIN, J.R.; ROSE, D. Working with discourse. Meaning beyond the clause. London: Continuum, 2003

. Genre relations. Mapping culture. London:Equinox, 2008. 
MARTIN, J.R.; WHITE, P.R.R. The language of evaluation - Appraisal in English. Londres: Palgrave Macmillan, 2005.

PROPP, V.I. Morfologia do conto maravilhoso. $2^{\mathrm{a}}$ edição. Rio de Janeiro: Forense Universitária, 2006.

SILVA, F.L. Felicidade - dos filósofos pré-socráticos aos contemporâneos. São Paulo: Editora Claridade, 2007.

VIAN JR, O. O planejamento de cursos instrumentais de produção oral com base em gêneros do discurso: mapeamento de experiências vividas e interpretações sobre um percurso. Tese de Doutorado.Programa de Estudos Pós Graduados em Lingüística Aplicada e Estudos da Linguagem (LAEL). PUCSP. 2002.

. O sistema de avaliatividade e os recursos para gradação em língua portuguesa: questões terminológicas e instanciação. Revista Delta, 25:1, 2009.

Recebido em: julho de 2010 Aprovado em: outubro de 2010 orlandovianjr@gmail.com 